\title{
Knowledge of Exclusive Breastfeeding among Nursing Mothers Attending under 5 Welfare Clinic in a Nigerian Tertiary Health Institution
}

\author{
N. C. Ekeleme, E. C. Iwuoha, S. N. Ijeoma, and P. I. Ejikem
}

\section{ABSTRACT}

Background: Exclusive Breastfeeding (EBF) offers important protective effects on child survival. Knowledge on EBF is a prerequisite to enhance its practice among nursing mothers.

Objective: To determine the knowledge of exclusive breastfeeding practice among nursing mothers attending Under-5 Welfare Clinic in a tertiary health facility in Nigeria.

\begin{abstract}
Materials and Methods: This was a cross-sectional descriptive study involving 333 nursing mothers. Pre-tested self/interviewer administered questionnaires were used to obtain information from consenting eligible women. Knowledge was assessed using a 12-point score and classified as good or poor. Data obtained was analyzed using IBM SPSS version 25.

Results: Our respondents had a mean age of $31 \pm 4$.9years while $84.7 \%$ were 27 years and above. Majority were married $(93.1 \%)$ with $57 \%$ of them having at least two (2) living children. Well over half of the respondents had attained a tertiary education. Antenatal care (ANC) was attended by $94.9 \%$ of the women where $96.8 \%$ said they had received advice on EBF. A total of $86 \%$ of the women had good knowledge score of EBF. Educational status and occupation showed statistically significant association with knowledge of EBF among the mothers $(p=<0.001$ and $p=0.018)$ respectively while marital status $(p=0.046)$, number of living children $(p=0.001)$, educational status $(p=<0.001)$ and occupation $(p=0.050)$ all showed significant association with $\mathrm{ANC}$ attendance.
\end{abstract}

Conclusion: The effect of female education on knowledge of health issues is brought to the fore by the findings of this study. More emphasis on delivering at health facilities where information to women on the practice of optimal breastfeeding is readily available will go a long way to reduce the infant and maternal mortality rates in Nigeria.

Keywords: Exclusive breastfeeding, Knowledge, Nursing mothers, Under-5 Clinic.

\section{INTRODUCTION}

Breast milk has the essential nutrients that a newborn need to grow healthy and strong. Adequate knowledge about exclusive breastfeeding is said to be the fundamental tool that can direct the course of EBF practice among mothers [1], [2]. Exclusive breastfeeding (EBF) is defined as exclusive intake of breast milk by an infant from its mother or wet nurse or expressed milk with addition of no other liquid or solid with the exception of drops or syrups consisting of vitamins, minerals supplements, or medicine and nothing else for the first six months [3].

Increasing breastfeeding prevalence to optimal levels has been identified by the Lancet's Series on Child Survival to reduce $13 \%$ of all child deaths in low income countries. ${ }^{4}$ The
Submitted : June 04, 2021

Published: June 26,2021

ISSN: $2593-8339$

DOI: $10.24018 /$ ejmed.2021.3.3.914

N. C. Ekeleme

Department of Community Medicine,

Abia State University Teaching

Hospital, Aba, Nigeria.

E. C. Iwuoha*

Department of Community Medicine, Abia State University Teaching Hospital, Aba, Nigeria.

(e-mail: iwuohacarol@gmail.com)

S. N. Ijeoma

Department of Paediatrics, Abia State University Teaching Hospital, Aba, Nigeria.

P. I. Ejikem

Department of Community Medicine, Abia State University Teaching Hospital, Aba, Nigeria.

*Corresponding Author
Global Burden of Diseases, Injuries and Risk Factor Study ranked Suboptimal breastfeeding as the second largest risk factor for children under five, accounting for the loss of 47.5 million Disability Adjusted Life Years (DALYs) in 2010 [5]. Sub-Saharan Africa has been the worst affected with the highest proportion of disease burden associated to suboptimal breastfeeding [5].

Marital status, place of delivery, maternal education and attitudes towards exclusive breastfeeding have been previously cited to improve Exclusive Breastfeeding [6]-[8].

\section{MATERIALS AND METHODS}

The study took place in Aba, the commercial hub of Abia State in southeast Nigeria. The residents are predominantly 
Ibos, majority are Christians, mostly traders and artisans with a smaller proportion being civil servants. This cross-sectional descriptive survey took place in August 2017. 333 nursing mothers attending Under-5 Welfare Clinic at the State Teaching hospital in Aba, Abia State, took part in this study and pre-tested self/interviewer administered questionnaires were used to obtain information from consenting eligible subjects on their clinic days. Knowledge was assessed using 6 questions; each correct answer scored 2 points giving a total of 12 points. Respondents who scored 7-12 points (i.e., above $50 \%$ ) had "Good knowledge score" while those with a score of $<7$ (50\% and below) had "Poor knowledge score"

Data obtained was checked for completeness, entered into and analyzed using IBM SPSS version 25. Descriptive statistics of the variables were presented in frequency tables. Relevant means, standard deviations and proportions were calculated. The Chi square test was used to determine associations between independent variables (such as Age, sex, marital status, educational status, religion etc.) and the outcome variable (Knowledge of exclusive breastfeeding).

\section{RESUltS}

TABLE I: SOCIO-DEMOGRAPHIC VARIABLES OF RESPONDENTS

\begin{tabular}{|c|c|c|}
\hline Variable & $\begin{array}{c}\text { Frequency } \\
(\mathrm{N}=333)\end{array}$ & $\begin{array}{c}\text { Percentage } \\
(\%)\end{array}$ \\
\hline \multicolumn{3}{|l|}{ Age group (in years) } \\
\hline $15-20$ & 3 & 0.9 \\
\hline $21-26$ & 48 & 14.4 \\
\hline $27-32$ & 176 & 52.9 \\
\hline $33+$ & 106 & 31.8 \\
\hline \multicolumn{3}{|l|}{ Marital status } \\
\hline Single & 13 & 3.9 \\
\hline Married & 310 & 93.1 \\
\hline Widowed & 4 & 1.2 \\
\hline Divorced & 6 & 1.8 \\
\hline \multicolumn{3}{|l|}{ Number of children } \\
\hline$<3$ & 190 & 57.1 \\
\hline $3+$ & 143 & 42.9 \\
\hline \multicolumn{3}{|l|}{ Religion } \\
\hline Christianity & 326 & 97.9 \\
\hline Islam & 7 & 2.1 \\
\hline \multicolumn{3}{|l|}{ Educational status } \\
\hline Primary or less & 23 & 6.9 \\
\hline Secondary & 116 & 34.8 \\
\hline Tertiary & 194 & 58.3 \\
\hline \multicolumn{3}{|l|}{ Occupation } \\
\hline Unemployed & 75 & 22.5 \\
\hline Self employed & 173 & 52.0 \\
\hline Civil servant & 85 & 25.5 \\
\hline \multicolumn{3}{|l|}{ Social habits } \\
\hline Alcohol intake & 61 & 18.3 \\
\hline Smokes cigarettes, heroine etc. & 3 & 0.9 \\
\hline Keeps boyfriends & 2 & 0.6 \\
\hline Not applicable & 267 & 80.2 \\
\hline
\end{tabular}

Mean age $=31 \pm 5.0$ years.

Table I above shows the socio-demographic variables of the respondents. Majority of the study participants $(52.9 \%)$ were in the 27-32 years age group with a mean age of $31 \pm 5.0$ years and most were married $(93.1 \%)$ with $42.9 \%$ having at least 3 children. Nearly all the respondents $(97.9 \%)$ were Christians, a higher proportion of respondents $(58.3 \%)$ had tertiary education while 173/333 (52\%) were self-employed. About $80 \%$ of the respondents had none of the social habits studied though $18 \%$ admitted to alcohol consumption.
TABLE II: REPRODUCTIVE INFORMATION

\begin{tabular}{|c|c|c|}
\hline Variable & $\begin{array}{l}\text { Frequency } \\
(\mathrm{N}=333)\end{array}$ & Percentage $(\%)$ \\
\hline \multicolumn{3}{|l|}{ Place of delivery } \\
\hline At home & 3 & 0.9 \\
\hline Church & 2 & 0.6 \\
\hline Maternity & 58 & 17.4 \\
\hline Hospital & 270 & 81.1 \\
\hline \multicolumn{3}{|l|}{ Mode of delivery } \\
\hline Normal (SVD) & 261 & 78.4 \\
\hline $\mathrm{C} / \mathrm{S}$ & 72 & 21.6 \\
\hline \multicolumn{3}{|l|}{ Birth weight of baby $(\mathrm{kg})$} \\
\hline$<2.5$ & 24 & 7.2 \\
\hline$\geq 2.5$ & 309 & 92.8 \\
\hline \multicolumn{3}{|l|}{ Birth order } \\
\hline $1^{\text {st }}$ child & 100 & 30.0 \\
\hline $2^{\text {nd }}$ child & 96 & 28.8 \\
\hline $3^{\text {rd }}$ child & 73 & 21.9 \\
\hline $4^{\text {th }}$ child or higher & 64 & 19.2 \\
\hline \multicolumn{3}{|l|}{ Did you attend ANC? } \\
\hline Yes & 316 & 94.9 \\
\hline No & 17 & 5.1 \\
\hline $\begin{array}{l}\text { If Yes, were you advised on } \\
\text { breastfeeding? }\end{array}$ & $\mathrm{n}=316$ & \\
\hline Yes & 306 & 96.8 \\
\hline No & 10 & 3.2 \\
\hline
\end{tabular}

Table II is on reproductive information of the mothers. A high proportion: $270 / 333(81.1 \%)$ delivered their current baby in a hospital while less than $1 \%$ had home delivery. Over three-quarters $(78.4 \%)$ of the mothers had a normal spontaneous vaginal delivery (SVD) and $92.8 \%$ had babies weighing $\geq 2.5 \mathrm{~kg}$ at birth. In birth order, $30 \%$ of the current babies was a " 1 st child", $28.8 \%$ " $2^{\text {nd }}$ child", $21.9 \%$ " $3^{\text {rd }}$ child" and $19.2 \%$ " 4 th child" or higher. A high proportion of them (94.9\%) attended Antenatal clinic where $96.8 \%$ said they were advised on breastfeeding.

TABLE III: KNOWLEDGE OF EXCLUSIVE BREASTFEEDING

\begin{tabular}{lcc}
\hline \multicolumn{1}{c}{ Variable } & $\begin{array}{c}\text { Frequency } \\
(\mathrm{N}=333)\end{array}$ & $\begin{array}{c}\text { Percentage } \\
(\%)\end{array}$ \\
\hline When should breastfeeding start? & & \\
Within an hour of delivery & 271 & 81.4 \\
After 1 or 2 days & 36 & 10.8 \\
After a week & 2 & 0.6 \\
Don't know & 24 & 7.2 \\
Have you heard of EBF? & 322 & \\
Yes & 11 & 96.7 \\
No & $\mathrm{n}=322$ & 3.3 \\
If Yes, what is it? & 2 & \\
Giving baby breast milk \& cereals & 22 & 0.6 \\
Giving BM \& water & 3 & 6.8 \\
Giving BM \& formula & 295 & 0.9 \\
Giving only breast milk & & 91.6 \\
How long should EBF be done? & 13 & \\
No idea & 1 & 3.9 \\
A month & 6 & 0.3 \\
3 months & 301 & 1.8 \\
6 months & 12 & 90.4 \\
9 months & & 3.6 \\
Do you know advantages of EBF? & 258 & 77.5 \\
Yes & 75 & 22.5 \\
No & 198 & 77.6 \\
If Yes, give 4 advantages & 57 & 22.4 \\
2-4 Correct responses & &
\end{tabular}

Table III above is on knowledge of Exclusive Breastfeeding (EBF). A large proportion of the women $(81.4 \%)$ knew that breastfeeding should begin within an hour of delivery. Nearly all the respondents $(96.7 \%)$ have heard of EBF and about $92 \%$ knew what it is (Giving baby only breast milk). About $90 \%$ of them know that EBF is given for 6 months, $77.5 \%$ know the advantages of EBF out of which a 
similar proportion could correctly give 2-4 advantages of EBF.

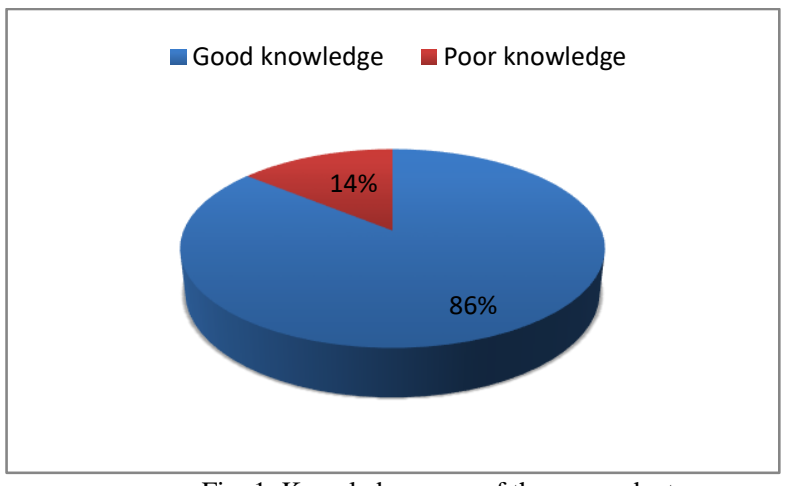

Fig. 1: Knowledge score of the respondents.

Fig. 1 above shows the knowledge score of the respondents. A total of 286/333 (85.9\%) had Good knowledge score while 47/333 (14.1\%) had Poor knowledge score.

TABLE IV: FACTORS ASSOCIATED WITH KNOWLEDGE OF EBF

\begin{tabular}{|c|c|c|c|c|}
\hline Variables & $\begin{array}{c}\text { Good } \\
\text { knowledge } \\
\mathrm{N}=286 \\
\mathrm{n}(\%)\end{array}$ & $\begin{array}{c}\text { Poor } \\
\text { knowledge } \\
\mathrm{N}=47 \\
\mathrm{n}(\%) \\
\end{array}$ & $\chi^{2}$ & p-value \\
\hline \multicolumn{5}{|l|}{ Age group (in years) } \\
\hline $15-20$ & $3(1.0)$ & $0(0.0)$ & \multirow{4}{*}{$1.772 *$} & \multirow{4}{*}{0.609} \\
\hline $21-26$ & $39(13.6)$ & $9(19.1)$ & & \\
\hline $27-32$ & $150(52.4)$ & $26(55.3)$ & & \\
\hline $33+$ & $94(32.9)$ & $12(25.5)$ & & \\
\hline \multicolumn{5}{|l|}{ Marital status } \\
\hline $\begin{array}{l}\text { Single } \\
\text { Married } \\
\text { Separated/divorce } \\
\text { d } \\
\text { Widowed }\end{array}$ & $\begin{array}{c}10(3.5) \\
268(93.7) \\
4(1.4) \\
4(1.4)\end{array}$ & $\begin{aligned} & (6.4) \\
42 & (89.4) \\
2 & (4.3) \\
0 & (0.0)\end{aligned}$ & $3.452^{*}$ & 0.246 \\
\hline \multicolumn{5}{|l|}{ Number of children } \\
\hline 1 & 89 (31.1) & $10(21.3)$ & \multirow{5}{*}{$3.260^{*}$} & \multirow{5}{*}{0.511} \\
\hline 2 & $79(27.6)$ & $12(25.5)$ & & \\
\hline 3 & $63(22.0)$ & $13(27.7)$ & & \\
\hline 4 & $37(12.9)$ & $9(19.1)$ & & \\
\hline$>4$ & $18(6.3)$ & $3(6.4)$ & & \\
\hline \multicolumn{5}{|l|}{ Educational status } \\
\hline None & $6(2.1)$ & $3(6.4)$ & \multirow{4}{*}{$34.438^{*}$} & \multirow{4}{*}{$<0.001 * *$} \\
\hline Primary & $8(2.8)$ & $6(12.8)$ & & \\
\hline Secondary & $88(30.8)$ & $28(59.6)$ & & \\
\hline Tertiary & $184(64.3)$ & $10(21.3)$ & & \\
\hline \multicolumn{5}{|l|}{ Occupation } \\
\hline Unemployed & $58(20.3)$ & $17(36.2)$ & \multirow{3}{*}{$8.024^{*}$} & \multirow{3}{*}{$0.018^{* *}$} \\
\hline Self employed & $149(52.1)$ & $24(51.1)$ & & \\
\hline Civil servant & $79(27.6)$ & $6(12.8)$ & & \\
\hline
\end{tabular}

*Fisher's Test.

**Statistical significance.
Table IV is on Socio-demographic variables and Knowledge score of EBF. Whereas respondents within the 27-32 age group, married with at least one child had good knowledge of EBF, the association was not significant ( $\mathrm{p}=0.609, \mathrm{p}=0.246$ and $\mathrm{p}=0.511$, respectively). Those who had attained a tertiary institution and self-employed had good knowledge of EBF and this was statistically significant $(\mathrm{p}<0.001$ and $\mathrm{p}=0.018)$.

Table $\mathrm{V}$ shows the association between socio-demographic variables and ANC attendance of the nursing mothers. Highest attendance was seen among respondents who were married with at least one child, had a tertiary education and were self-employed. These variables also showed statistically significant association with ANC attendance $(\mathrm{p}=0.046$, $\mathrm{p}=0.001, \mathrm{p}=<0.001$ and $\mathrm{p}=0.050$ respectively). Respondents aged 27-32 years had high ANC attendance which was not statistically significant $(\mathrm{p}=0.099)$.

TABLE V: FACTORS INFLUENCING ANC ATTENDANCE

\begin{tabular}{|c|c|c|c|c|}
\hline Variables & $\begin{array}{c}\mathrm{ANC} \\
\text { attendance } \\
\text { Yes } \\
\mathrm{N}=316 \\
\mathrm{n}(\%) \\
\end{array}$ & $\begin{array}{c}\text { No } \\
\mathrm{N}=47 \\
\mathrm{n}(\%)\end{array}$ & $\chi^{2}$ & p-value \\
\hline \multicolumn{5}{|l|}{ Age group (in years) } \\
\hline $15-20$ & $3(100.0)$ & $0(0.0)$ & \multirow{4}{*}{$5.953 *$} & \multirow{4}{*}{0.099} \\
\hline $21-26$ & $46(95.8)$ & $2(4.2)$ & & \\
\hline $27-32$ & $171(97.2)$ & $5(2.8)$ & & \\
\hline $33+$ & $96(90.6)$ & $10(9.4)$ & & \\
\hline \multicolumn{5}{|l|}{ Marital status } \\
\hline Single & $12(92.3)$ & $1(7.7)$ & \multirow{4}{*}{$7.341 *$} & \multirow{4}{*}{$0.046 * *$} \\
\hline Married & $296(95.5)$ & $14(4.5)$ & & \\
\hline Separated/divorced & $4(66.7)$ & $2(33.3)$ & & \\
\hline Widowed & $4(100.0)$ & $0(0.0)$ & & \\
\hline \multicolumn{5}{|l|}{ Number of children } \\
\hline 1 & $99(100.0)$ & $0(0.0)$ & \multirow{5}{*}{$16.006^{*}$} & \multirow{5}{*}{$0.001 * *$} \\
\hline 2 & $87(95.6)$ & $4(4.4)$ & & \\
\hline 3 & $69(90.8)$ & $7(9.2)$ & & \\
\hline 4 & $44(95.7)$ & $2(4.3)$ & & \\
\hline$>4$ & $17(81.0)$ & $4(19.0)$ & & \\
\hline \multicolumn{5}{|l|}{ Educational status } \\
\hline None & $5(55.6)$ & $4(44.4)$ & \multirow{4}{*}{$41.006^{*}$} & \multirow{4}{*}{$<0.001^{* *}$} \\
\hline Primary & $8(57.1)$ & $6(42.9)$ & & \\
\hline Secondary & $111(95.7)$ & $5(4.3)$ & & \\
\hline Tertiary & $192(99.0)$ & $2(1.0)$ & & \\
\hline \multicolumn{5}{|l|}{ Occupation } \\
\hline Unemployed & $67(89.3)$ & $8(10.7)$ & \multirow{3}{*}{$3.913^{*}$} & \multirow{3}{*}{$0.050 * *$} \\
\hline Self employed & $167(96.5)$ & $6(3.5)$ & & \\
\hline Civil servant & $82(96.5)$ & $3(3.5)$ & & \\
\hline
\end{tabular}

TABLE VI: MULTIVARIATE LOGISTIC REGRESSION OF KNOWLEDGE SCORE USING PREDICTOR FACTORS IDENTIFIED IN UNIVARIATE LOGISTIC REGRESSION

\begin{tabular}{|c|c|c|c|c|c|c|}
\hline \multirow{2}{*}{$\begin{array}{c}\text { Independent } \\
\text { Variable }\end{array}$} & \multicolumn{6}{|c|}{ Knowledge score } \\
\hline & $\begin{array}{c}\text { Good } \\
\text { knowledge }\end{array}$ & $\begin{array}{c}\text { Poor } \\
\text { knowledge }\end{array}$ & $\begin{array}{l}\text { Crude odds } \\
\text { ratio(cOR) }\end{array}$ & P-value & $\begin{array}{l}\text { Adjusted odds } \\
\text { ratio(aOR) }\end{array}$ & P-Value \\
\hline \multicolumn{7}{|l|}{ Marital status } \\
\hline Married & 268 & 42 & 1 & & 1 & \\
\hline Other status & 18 & 5 & $1.77(0.63-5.03)$ & 0.28 & $1.85(0.63-5.47)$ & 0.27 \\
\hline \multicolumn{7}{|l|}{ No. of children } \\
\hline$<3$ & 168 & 22 & 1 & & 1 & \\
\hline $3+$ & 118 & 25 & $1.62(0.87-3.01)$ & 0.13 & $1.61(0.85-3.06)$ & 0.15 \\
\hline \multicolumn{7}{|l|}{ Educational status } \\
\hline Primary or less & 14 & 9 & 1 & $0.001^{*}$ & 1 & $0.008 *$ \\
\hline Secondary \& above & 272 & 38 & $0.22(0.09-0.54)$ & & $0.29(0.11-0.72)$ & \\
\hline \multicolumn{7}{|l|}{ Occupation } \\
\hline Unemployed & 207 & 41 & 1 & $0.04 *$ & 1 & 0.07 \\
\hline Employed & 79 & 6 & $0.38(0.16-0.94)$ & & $0.43(0.17-1.07)$ & \\
\hline
\end{tabular}


Table VI shows odds ratios for predictors of knowledge of EBF from univariate and multivariate logistic regression at 95\% confidence interval (C.I.). Univariate analysis was done for marital status, number of children, educational level, and occupation. Educational level and occupation showed a statistical association at univariate level. On adjustment during multivariate logistic regression analysis, only educational level was found to be a significant predictor of knowledge of EBF among the mothers $(\mathrm{p}=0.008)$. Those with a secondary education or higher were 3 times more likely to have good knowledge of EBF than those with a primary education or less.

\section{DISCUSSION}

In this study, most of the respondents were between the age group 27-32 years and more than $90 \%$ were married which is similar to other studies done in Sagamu, Southwest Nigeria, Kenya and India [9]-[11]. Most of the respondents had tertiary education which is in contrast to a study done in Italy where $60.6 \%$ of the respondents had secondary education [12]. However, the above finding in Italy was different in another study done in Ekiti State Nigeria, which also had similar findings to our study [13]. This goes to show that educated women are more likely to attend ANC.

Approximately $80 \%$ of the respondents in our study had a source of income by either being government workers or selfemployed, contrasting other studies done in Europe, in which more than half of their participants $(53.6 \%)$ were unemployed [12].

The parity of majority of respondents ranged between 1 and 3 and corroborates with a South African and Ethiopian study [14], [15]. This also shows effective utilization of family planning available at these tertiary health institutions by the women.

In this study, majority of the respondents (81\%) had hospital delivery with more $(94.9 \%)$ attending ANC and also admitted to being advised on breastfeeding. Studies have found history frequency of $\mathrm{ANC}$, place, and mode of delivery; and maternal education to be significantly associated with timely initiation of breastfeeding [16]-[18].

This study found majority (97\%) of the participants having heard about exclusive breastfeeding, out of these, $92 \%$ knew the correct meaning of exclusive breastfeeding and about $81 \%$ knew that breastfeeding should be initiated within 30 minutes to one hour following delivery. Also, majority (90\%) of the respondents knew that exclusive breastfeeding should be done for six completed months, and more than half of the study participants could state at least two advantages of exclusive breast feeding. These findings show that there is good knowledge of exclusive breastfeeding among our study participants. The good knowledge of exclusive breastfeeding in this study is in agreement with a similar study done in Accra Ghana [19] but in contrast with another study done in Gwale, Kano where only a third of the respondents had good knowledge of exclusive breastfeeding [20]. However, the study done by Freed et al., obtained another low value of about half of their respondents having good knowledge of exclusive breastfeeding [21].

On the actors affecting knowledge score of exclusive breastfeeding in our study; respondents within the age-group of 27-32 years, married and with at least one child had good knowledge of exclusive breastfeeding. This was however not statistically significant, whereas those who had attained a tertiary institution and are self-employed had good knowledge of exclusive breastfeeding and was found to be statistically significant. In other studies, factors found to be associated with exclusive breastfeeding were mothers' occupation, frequency of ANC visits, breastfeeding advice during ANC, and mode of delivery [22]-[24]. The findings in our study were however similar to studies done in Sokoto, Kano, and Ilorin; northern Nigeria, which found a statistically significant relationship between maternal age and education, maternal occupation, parity, family income and exclusive breastfeeding [20], [25], [26]. In studies done in Jos, Sokoto, and Kenya; maternal age was however not associated with the practice of exclusive breastfeeding [25], [27], [28].

\section{CONCLUSION}

Most of our study participants were educated and gainfully employed resulting in their having good knowledge of exclusive breastfeeding and its benefits to the infant. Hence it is recommended that female education be advocated. More emphasis on delivering at health facilities where information to women on the practice of optimal breastfeeding is readily available will go a long way to reduce the infant and maternal mortality rates in Nigeria.

\section{REFERENCES}

[1] Ayawine A, Ayuurebobi K. Determinants of exclusive breastfeeding: a study of two sub-districts in the AtwimaNwabiagya District of Ghana. The Pan African Medical Journal. 2015;22. https://doi.org/10.11604/pamj.2015.22.248.6904.

[2] Kiragu R, Neupane JE, Kandel S. Knowledge, attitude and challenges of exclusive breastfeeding among primigravidas; 2014 https://www.theseus.fi/bitstream/handle/10024/71668/student_reginah

[3] WHO/UNICEF, "Innocenti Declaration 2005: On Infant and Young Child Feeding. "Celebrating Innocenti 1990-2005: Achievements, Challenges and Future Imperatives," Florence, Italy, 2005, http://innocenti15.net/declaration.pdf.pdf.

[4] Jones G, Steketee RW, Black RE, Bhutta ZA, Morris SS, Group BCSS. How many child deaths can we prevent this year? The Lancet 2003;362:65-71.

[5] Lim SS, Vos T, Flaxman AD, Danaei G, Shibuya K, Adair-Rohani H, AlMazroa MA, Amann M, Anderson HR, Andrews KG. A comparative risk assessment of burden of disease and injury attributable to 67 risk factors and risk factor clusters in 21 regions, 1990-2010: a systematic analysis for the global burden of disease study 2010. The Lancet 2013;380:2224-60.

[6] Tampah-Naah AM, Kumi-Kyereme A. Determinants of exclusive breastfeeding among mothers in Ghana: a cross-sectional study. International Breastfeeding Journal. 2013;8:13.

[7] Aryeetey RNO, Antwi CL. Re-assessment of selected Baby-Friendly maternity facilities in Accra. Ghana International Breastfeeding Journal. 2013;8:1.

[8] Lawoyin T, Olawuyi J, Onadeko M. Factors associated with exclusive breastfeeding in Ibadan, Nigeria. Journal of Human Lactation. 2001; $17: 321-5$.

[9] Sholeye OO, Abosede OA, Salako AA. Exclusive Breastfeeding and Its Associated Factors among Mothers in Sagamu, Southwest Nigeria. J Heal Sci [Internet]. 2015;5(2):25-31

[10] Cherop C, Keverenge-Ettyang A, Mbagaya G. Barriers To Exclusive Breastfeeding Among Infants Aged 0-6 Months In Eldoret Municipality, Kenya. East Afr J Public Health. 2009 Apr 1;6:69-72.

[11] Kishore MSS, Kumar P, Aggarwal AK. Breastfeeding knowledge and practices amongst mothers in a rural population of North India: A community-based study. J Trop Pediatr. 2009;55(3):183-8. 
[12] Cascone D, Tomassoni D, Napolitano F, Di Giuseppe G. Evaluation of knowledge, attitudes, and practices about exclusive breastfeeding among women in Italy. Int J Environ Res Public Health. 2019.

[13] Ijarotimi OS. Assessing exclusive breastfeeding practices, dietary intakes and body mass index (BMI) of nursing mothers in Ekiti State of Nigeria. Nutr Res Pract. 2010;4(3):222.

[14] Nyaloko M, Lubbe W, Minnie K. Perceptions of Mothers and Community Members Regarding Breastfeeding in Public Spaces in Alexandra, Gauteng Province, South Africa. Open Public Health J. 2020;13(1):582-94.

[15] Alamirew MW, Bayu NH, Birhan Tebeje N, Kassa SF. Knowledge and Attitude towards Exclusive Breast Feeding among Mothers Attending Antenatal and Immunization Clinic at Dabat Health Center, Northwest Ethiopia: A Cross-Sectional Institution Based Study. Nurs Res Pract. 2017;2017:1-9.

[16] Berhe HH, Mekonnen B, Bayray A, Berhe HH. Determinants of breast feeding practices among mothers attending public health facilities, Mekelle, northern Ethiopia; a cross sectional study. Int J Pharm Sci Res [Internet]. 2013;4(2):650-60. Available from: https://pdfs.semanticscholar.org/2552/86c5d7767f48d06f17d39bf18d 08b2053c9e.pdf?_ga=2.28417404.1759822155.1570122728578834258.1568201966.

[17] Dearden K, Altaye M, De Maza I, De Oliva M, Stone-Jimenez M, Morrow AL, et al. Determinants of optimal breast-feeding in peri-urban Guatemala City, Guatemala. Rev Panam Salud Publica. 2002 Sep;12(3):185-92.

[18] Tesfaye S, Belachew T, Gerbaba M. Determinants of timely breastfeeding initiation among mothers in goba woreda south east Ethiopia: a cross sectional study. BMC Public Health [Internet]. 2011;11. Available from: https://doi.org/10.1186/1471-2458-11-21
[19] Aidam BA, Pérez-Escamilla R, Lartey A, Aidam J. Factors associated with exclusive breastfeeding in Accra, Ghana. Eur J Clin Nutr. 2005;59(6):789-96.

[20] Iliyasu Z, Kabir M, Abubakar I, Galadanci N. Current knowledge and practice of exclusive breastfeeding among mothers in Gwale loca government area of Kano State. Niger Med Pract. 2006 Jan 4;48.

[21] Freed GL, Clark SJ, Sorenson J, Lohr JA, Cefalo R, Curtis P. National assessment of physicians' breast-feeding knowledge, attitudes, training, and experience. JAMA. 1995 Feb;273(6):472-6.

[22] Radhakrishnan S, Balamuruga Ss. Prevalence of exclusive breastfeeding practices among rural women in Tamil Nadu. Int J Heal Allied Sci. 2012;1(2):64

[23] Mohan L. Patterns and Determinants of Breast Feeding Practices in Dodoma Municipality: A Cross Sectional Study. J Food Stud. 2012 Jul $11 ; 1$.

[24] Patil S, Hasamnis A, S P, Aarti P, Khan A, K A N. Prevalence Of Exclusive Breast Feeding And Its Correlates In An Urban Slum In Western India. Int J Sci Med Educ. 2009 Dec 1;3.

[25] Umar AS, Oche MO. Breastfeeding and weaning practices in an Urban Slum, North Western Nigeria. Int J Trop Dis Heal [Internet] 2013;3(2):114-25. Available from: www.sciencedomain.org.

[26] Fagbule DO, Olaosebikan A. Weaning practices in Ilorin community, Nigeria. West Afr J Med. 1992.

[27] Ogbonna C, Daboer JC. Current knowledge and practice of exclusive breastfeeding among mothers in Jos, Nigeria. Niger J Med. 2007.

[28] Nyanga NM, Musita C, Otieno A, Kaseje D. Factors influencing knowledge and practice of exclusive breastfeeding in Nyando District, Kenya. African J Food, Agric Nutr Dev. 2012. 